\title{
Fenilcetonúria no Brasil: evolução e $\operatorname{casos}^{1}$
}

\author{
Phenylketonuria in Brazil: evolution and cases
}

Lenice Teresinha Bussolotto MONTEIRO2,3

Lys Mary Bileski CÂNDIDO 4

RE S U M O

Os objetivos deste trabalho foram: agrupar informações relevantes à fenilcetonúria, destacando causa, sintomas, tratamento dietético, prevalência nacional e internacional; e identificar a situação do Brasil quanto a essa disfunção metabólica. Foi realizado um levantamento de dados junto ao Ministério da Saúde e aos vários centros de tratamento para fenilcetonúricos no Brasil. Neste estudo foram localizados 1225 casos de portadores da doença, que recebiam controle e assistência. Um dos principais problemas detectados foi que, na maioria das regiões brasileiras, portadores de fenilcetonúria precisam deslocar-se de seus estados, procurando centros mais capacitados para o tratamento. Nas regiões Norte e Nordeste são poucas as informações disponíveis. Com os resultados obtidos conclui-se que, nem a triagem neonatal, nem os centros de tratamento para fenilcetonúria cobrem todos os casos brasileiros. O Brasil está avançando na organização de dados e ações relativas à fenilcetonúria. Os alimentos específicos são restritos e de alto custo. Novas opções estão sendo pesquisadas, porém, há muito para ser feito, principalmente em pesquisa e produção de alimentos.

Termos de indexação: erros inatos do metabolismo; fenilcetonúria; triagem neonatal.

\section{A B S T R A C T}

The objectives of this work were to gather relevant information on phenylketonuria, highlighting the cause, symptoms, dietary treatment, national and international prevalence and to identify the situation of this metabolic disorder in Brazil. Data were obtained from the National Ministry of Health and phenylketonuria treatment units in Brazil. In this study, 1225 people who received control and assistance for the disease were included. One of the main problems detected was that in most of Brazil, phenylketonuria patients have to leave their home state seeking more qualified treatment centers. In the Northern and Northeastern Regions,

\footnotetext{
1 Artigo elaborado a partir da dissertação de L.T.B. MONTEIRO, intitulada "Desenvolvimento de uma formulação protéica com teor reduzido de fenilalanina". Programa de Pós-Graduação em Tecnologia de Alimentos. Universidade Federal do Paraná; 2003.

2 Programa de Pós-Graduação em Tecnologia de Alimentos, Setor de Tecnologia, Universidade Federal do Paraná. R. Lothário Meisner, 632, Jd. Botânico, 80210-170, Curitiba, PR, Brasil. Correspondência para/Correspondence to: L. T.B. MONTEIRO. E-mail: <enice.monteiro@brturbo.com.br>.

3 Departamento de Nutrição, Pontifícia Universidade Católica do Paraná. Curitiba, PR, Brasil.

4 Programa de Pós-Graduação em Ciências Farmacêuticas, Departamento de Nutrição, Universidade Federal do Paraná. Curitiba, PR, Brasil.
} 
little information is available. The results obtained lead to the conclusion that neither newborn screening, nor phenylketonuria treatment centers cover all of the Brazilian cases. Advances in organizing data and actions regarding phenylketonuria have been taking place. Specific foods are restrict and costly. New options are being researched, nevertheless, there is much to be done, mainly on food research and production.

Indexing terms: metabolism, inborn errors; Phenylketonuria; neonatal screening.

\section{N T R O D U Ç Ã O}

A fenilcetonúria ou PKU, como é mundialmente conhecida, é uma doença genética, causada por uma mutação no gene que codifica a enzima fenilalanina-hidroxilase, ativa no fígado e responsável pela transformação do aminoácido fenilalanina (PHE) em tirosina. A elevação de fenilalanina no sangue, acima de $10 \mathrm{mg} / \mathrm{dl}$, permite a passagem em quantidade excessiva para o Sistema Nervoso Central, no qual o acúmulo tem efeito tóxico. O retardo mental é a mais importante seqüela dessa doença.

No Brasil, a prevalência de fenilcetonúria, segundo o Ministério da Saúde (MS), era estimada em 1:12 a 15 mil nascidos vivos. De acordo com Carvalho', em 2001 a prevalência ficou em 1:15.839 e em 2002 foi de 1 por 24780.

A doença é detectada pelo "teste do pezinho", cuja obrigatoriedade, para todo o território brasileiro, consta no Estatuto da Criança e do Adolescente, inciso III do Artigo 10 da Lei $n^{\circ} 8069$, de 13/07/1990².

Baseando-se nos conhecimentos atuais, se todos os recém-nascidos pudessem ter acesso à triagem neonatal, seriam possíveis o diagnóstico precoce de fenilcetonúria e o controle da doença, com tratamento dietético adequado. O tratamento é dietético, consistindo na exclusão ou substituição de todos os alimentos fornecedores de fenilalanina. A alimentação com baixo teor de fenilalanina deve ser introduzida no primeiro mês de vida, e mantida pela vida inteira ${ }^{3}$. Essa recomendação é variável, seguindo também para a fase adulta ${ }^{4}$.

O adequado aporte protéico não é conseguido, pela alimentação convencional, sem que quantidades excessivas de PHE sejam ingeridas por esses pacientes. Nas proteínas alimentares o teor médio de PHE é da ordem de 2,4\% a 9,0\% $\%^{5}$. Com o controle dietético a deficiência mental, ocasionada por essa disfunção, deixará de ocorrer, o que requer produzir e disponibilizar alimentos adequados.

A introdução de uma dieta reduzida em fenilalanina na alimentação da criança, no primeiro mês de vida, pode evitar significativamente o retardo mental. A dieta restrita em fenilalanina é necessária para prevenir, também, os diversos efeitos decorrentes da elevação da sua concentração plasmática durante a gravidez, que incluem microcefalia e anormalidades físicas ${ }^{6-8}$.

O objetivo deste trabalho foi reunir informações sobre a fenilcetonúria e identificar a situação no Brasil quanto a essa disfunção metabólica, servindo como referência e apoio para o trabalho de profissionais envolvidos com a doença.

\section{FE N I L C E T O N Ú R I A}

As alterações metabólicas geneticamente determinadas são chamadas de erros inatos do metabolismo (EIM). A característica essencial dos EIM é uma dependência específica na atividade de uma enzima em particular, por síntese protéica alterada. A fenilcetonúria é uma doença metabólica, transmitida geneticamente de forma autossômica recessiva. É a mais grave das hiperfenilalaninemias, causada pela deficiência da enzima fenilalanina-hidroxilase, e o não tratamento é associado com o alto risco do desenvolvimento cognitivo prejudicado ${ }^{9}$. Não há anormalidades aparentes ao nascimento, pois o fígado materno protege o feto ${ }^{10}$. Os níveis sangüíneos de fenilalanina do recém-nascido fenilcetonúrico aumentam nas primeiras semanas com alimentação protéica, incluindo o leite materno. 
As crianças não tratadas não conseguem atingir os marcos necessários iniciais de desenvolvimento, podendo apresentar comprometimento progressivo na função cerebral. Desenvolvem-se sintomas, como irritabilidade, dificuldade de aprendizado, falta de atenção, distúrbios comportamentais, hiperatividade e crises convulsivas entre os 6 e 18 meses de vida ${ }^{3,11}$.

A manifestação clínica mais grave é o retardo mental7, 12-14. De acordo com Waitzberg ${ }^{11}$, um paciente pode perder, em média, cinco unidades de Quociente de Inteligência (QI) a cada 10 semanas de atraso no tratamento.

A fenilalanina em excesso, e seus catabólitos, têm efeito tóxico nas funções somáticas e do sistema nervoso central, interferem na síntese protéica cerebral e mielinização, diminuem a formação de serotonina e alteram a concentração de aminoácidos no líquor. Essas alterações determinam a perda de funções, especialmente da capacidade intelectual do portador ${ }^{15}$.

Outras anormalidades eletroencefalográficas; o odor "de rato" da pele, dos cabelos e da urina, devido ao acúmulo de fenilacetato; e a tendência à hipopigmentação e eczema, completam o quadro clínico. O cheiro característico, quando presente, impregna o local onde esteja internado um paciente com fenilcetonúria. Em contraste, as crianças acometidas, detectadas ao nascimento e tratadas imediatamente, em regra, não exibem quaisquer dessas anormalidades ${ }^{16}$.

Investigações neuropsicológicas, com pacientes portadores de fenilcetonúria, confirmam a relação entre a disfunção com a degeneração de tecidos nervosos brancos do cérebro. Também comprovam que a utilização da dieta restrita em fenilalanina é eficaz na prevenção da deterioração neurológica e/ou psiquiátrica ${ }^{17-20}$.

\section{Tratamento}

Atualmente, preconiza-se que o tratamento dietético deve ser mantido durante toda a vida, já que, mesmo após o desenvolvimento neurológico completo do indivíduo, os níveis altos de fenilalanina podem alterar as funções cognitivas.

Moats et al. ${ }^{4}$, em estudo com 10 mil casos de pessoas com fenilcetonúria nos Estados Unidos, constataram que recém-nascidos diagnosticados e tratados com dieta restrita em fenilalanina têm desenvolvimento neurológico normal.

De acordo com Fauci et al. ${ }^{16}$, diversas mulheres com fenilcetonúria, e que foram tratadas desde a lactância, chegaram à idade adulta e engravidaram. Se os níveis de fenilalanina não forem estritamente controlados antes e no decorrer da gravidez, a criança estará sob o risco da fenilcetonúria materna. Ao nascimento, essas crianças apresentam microcefalia e risco aumentado de defeitos congênitos.

Segundo Karam²1, a triagem neonatal permite o diagnóstico e tratamento precoce e, assim, o desenvolvimento de uma geração de mulheres intelectualmente normais e capazes de reproduzir.

Em estudos de Cerone et al. ${ }^{22}$, avaliando a aceitabilidade e adequação nutricional de mistura de aminoácidos livre de fenilalanina, o crescimento normal foi mantido.

Os alimentos permitidos na alimentação de fenilcetonúricos são os que contêm baixos teores de fenilalanina (zero a 20mg PHE/100g de alimento). Estão incluídos: mel, balas de frutas e de gomas, pirulitos de frutas, picolés de frutas, algodão-doce, geléias de frutas, goiabada; farinha de tapioca, polvilho de mandioca, sagu. Entre as bebidas estão os sucos de frutas artificiais, refrigerantes isentos de aspartame, groselha, café, chá; e alguns cremes e pudins nos sabores baunilha, morango e caramelo e pós para milk-shake isentos de PHE.

Os alimentos proibidos na fenilcetonúria são os que têm alto teor de fenilalanina. Entre eles estão as carnes e derivados, o feijão, ervilha, soja, grão-de-bico, lentilha, amendoim, leite e derivados, achocolatado, ovos, nozes, gelatinas, bolos, farinha de trigo, alimentos industrializados 
com altos teores de fenilalanina, pães em geral, biscoitos, e alimentos para fins especiais contendo aspartame.

Alimentos com médio teor de fenilalanina (10 - 200mg PHE/100g do alimento) podem ser fornecidos na dieta, de acordo com a prescrição desse aminoácido. As quantidades desses alimentos são determinadas pela idade, tolerância individual e níveis séricos apresentados periodicamente. São as massas feitas sem ovos e com farinha de trigo de baixo teor de proteína, arroz, batata-inglesa, batata-doce, batata-salsa, mandioca, cará, abóbora, abobrinha, berinjela, beterraba, brócolis, cenoura, chuchu, couve-flor, jiló, quiabo, repolho, vagem, tomate, pepino, pimentão, cebola, folhosos e frutas em geral.

Segundo Sarkissian \& Gaméz ${ }^{9}$ tratamentos alternativos têm sido propostos para a fenilcetonúria, mas ainda estão em fase experimental. Um desses é a administração de tetrahidrobiopterina $\left(\mathrm{BH}_{4}\right)$ ou a terapia de substituição enzimática com fenilalanina amônia liase recombinante (PAL). Essa enzima converte PHE a metabólitos não tóxicos, como ácido trans-cinâmico. A administração pode ser oral ou sub-cutânea, mas o uso prolongado tem levado a uma resposta imune. Novas preparações da PAL estão sendo estudadas para minimizar o efeito.

\section{Perfil epidemiológico da fenilcetonúria}

Mundialmente, a prevalência da doença (Tabela 1) varia conforme a população analisada. Os números, em geral, vão de um caso para cada 10 mil ou 30 mil nascidos-vivos. É mais freqüente em caucasianos e menos freqüente em judeus Askenazi. Na Finlândia, praticamente não existe, na Islândia há uma incidência de 1:6000 e no Japão, 1:60000³.

No Brasil, o Estatuto da Criança e do Adolescente (Lei Federal n 8069, de 13 de julho de 1990) determina que os hospitais e demais estabelecimentos de atenção à saúde de gestantes, quer públicos ou particulares, procedam a
Tabela 1. Ocorrência mundial de fenilcetonúria por região ou grupo étnico.

\begin{tabular}{lcc}
\hline $\begin{array}{l}\text { Regiões geográficas } \\
\text { ou grupos étnicos }\end{array}$ & $\begin{array}{c}\text { Incidência (casos/ milhão } \\
\text { de nascimentos) }\end{array}$ & Prevalência \\
\hline Turquia & 385 & $1: 2597$ \\
Judeus lemenitas & 190 & $1: 5263$ \\
Escócia & 190 & $1: 5263$ \\
Tcheco Eslováquia & 150 & $1: 6666$ \\
Polônia & 130 & $1: 7692$ \\
Hungria & 90 & $1: 11111$ \\
Dinamarca & 85 & $1: 11764$ \\
França & 75 & $1: 13330$ \\
Noruega & 70 & $1: 14285$ \\
Inglaterra & 70 & $1: 14285$ \\
Itália & 60 & $1: 16666$ \\
China & 60 & $1: 16666$ \\
Canadá & 45 & $1: 22222$ \\
Brasil & 40 & $1: 24780$ \\
Suécia & 25 & $1: 40000$ \\
Japão & 7 & $1: 142857$ \\
Judeus Asquenazes & 5 & $1: 200000$ \\
Finlândia & 5 & $1: 200000$ \\
\hline
\end{tabular}

Fonte: Carvalho ${ }^{1}$, adaptado de Scriver et al ${ }^{14}$.

exames visando ao diagnóstico e terapêutica de anormalidades no metabolismo do recém-nascido, bem como prestar orientação aos pais².

A partir dessa data, alguns estados criaram seus programas, realizando gratuitamente o exame. As secretarias de saúde dos estados iniciaram a criação dos programas estaduais de triagem neonatal em torno de 1992-1993. O Programa Nacional de Triagem Neonatal (PNTN) ${ }^{23}$, foi criado, em 6 de junho de 2001, e implantado em outubro do mesmo ano. Problemas, como difícil acesso e carência de profissionais habilitados, dificultam o funcionamento do programa.

Em levantamento feito no Brasil, por Carvalho', em 2001 foram triadas 1,251 milhões de crianças, constatando 79 casos positivos para fenilcetonúria, e prevalência de 1:15 839. Em 2002 foram triadas 1,382 milhões de crianças, constatando 56 casos positivos e prevalência de 1:24 780. Os dados de 2001 e 2002, levantados pela Sociedade Brasileira de Triagem Neonatal, se referem a 18 dos 27 estados brasileiros. Faltaram os estados do Amazonas, Amapá, Mato 
Grosso, Pará, Piauí, Rio Grande do Norte, Roraima, Sergipe e Tocantins.

Ramalho et al. ${ }^{24}$ fizeram um levantamento da evolução do programa de triagem neonatal para a fenilcetonúria em Sergipe, no período de 1995 a 2003. A cobertura, em 2003, para o interior, foi de $67 \%$, e $85 \%$ para a Capital contra 5\% e 42\%, respectivamente, em 1995.

No Brasil, a maior dificuldade na obtenção dos dados de prevalência é que não há informações centralizadas. Para reunir as informações foi necessário fazer uma pesquisa junto ao Ministério da Saúde (Brasília) e aos centros de tratamento de portadores de fenilcetonúria, em 11 estados brasileiros. Nos demais estados não foi constatado controle da doença.

Para efeito deste levantamento, foram considerados portadores de fenilcetonúria crianças com diagnóstico detectado pela triagem neonatal ou tardiamente, em tratamento nos centros de atendimento de cada estado (não considerando a origem dos pacientes, visto que alguns centros de tratamento recebem pacientes de diversos estados brasileiros). Portadores de fenilcetonúria dos estados menos equipados necessitam deslocar-se para outros estados com freqüência, em busca de assistência e controle. Constatou-se que, no Brasil, fazem parte do controle e assistência 1225 casos, distribuídos conforme o apresentado na Tabela 2.

Segundo levantamento da Sociedade Brasileira de Triagem Neonatal (SBTN), apresentado em novembro de 2001, em Curitiba, PR, no $1{ }^{\circ}$ Congresso Brasileiro de Triagem Neonatal, em pesquisa efetuada em dez estados brasileiros (São Paulo, Rio de Janeiro, Paraná, Rio Grande do Sul, Mato Grosso do Sul, Goiás, Minas Gerais, Bahia, Santa Catarina, Maranhão), com 95\% de resposta, até o ano de 2000 haviam sido triadas 13,32 milhões de crianças para investigação de fenilcetonúria, sendo detectados 861 casos positivos e prevalência de 1:15.500. Dos que responderam à SBTN, apenas quatro serviços iniciaram o tratamento antes da criança completar 30 dias.
Tabela 2. Portadores de fenilcetonúria em tratamento no Brasil.

\begin{tabular}{|c|c|c|c|}
\hline Regiões & Estados & Portadores de PKU* & Habitantes** \\
\hline \multirow[t]{3}{*}{ Sul } & RS & 82 & 10187798 \\
\hline & SC & 37 & 5356360 \\
\hline & PR & 103 & 9563458 \\
\hline \multirow[t]{4}{*}{ Sudeste } & $\mathrm{SP}$ & 580 & 37032403 \\
\hline & MG & 118 & 17891494 \\
\hline & RJ & 205 & 14391282 \\
\hline & ES & 17 & 3097232 \\
\hline \multirow[t]{4}{*}{ Centro-Oeste } & MS & 6 & 2078001 \\
\hline & MT & 4 & 2504353 \\
\hline & $\mathrm{GO}$ & 29 & 5003228 \\
\hline & DF & 28 & 2051146 \\
\hline \multirow[t]{2}{*}{ Nordeste } & $\mathrm{BA}$ & 16 & 13070250 \\
\hline & Outros & $\star * *$ & 34671461 \\
\hline Norte & Todos & $* * *$ & 12900704 \\
\hline Total nacional & & 1225 & \\
\hline
\end{tabular}

Nos dados preliminares do PNTN, informados pelo grupo técnico de assessoria em triagem neonatal do Ministério da Saúde, publicados em 2003, constam 31 Serviços Regionais de Triagem Neonatal (SRTN) credenciados, em 23 dos 27 estados brasileiros. Nesses serviços regionais estão em acompanhamento 985 pacientes com fenilcetonúria ${ }^{26}$.

Considerando-se as informações divulgadas pelos órgãos oficiais e comparando-as com os resultados obtidos na pesquisa com os centros de tratamento para fenilcetonúria, somados à inexistência de controles de algumas regiões e ao pouco tempo da obrigatoriedade do teste para a detecção da doença, conclui-se que não se tem conhecimento de todos os casos brasileiros, principalmente de portadores de mais de 15 anos de idade.

No "teste do pezinho" o sangue do bebê é depositado em um papel de filtro. Após a solubilização, a amostra é submetida ao método de análise (Wallac's Kit Neonatal para Fenilalanina, da Perkin Elmer), o qual se baseia na intensificação da fluorescência da reação de fenilalanina-ninhidrina, produzida pelo dipeptídeo, 
L-leucil-L-alanina. A fluorescência é proporcional à concentração de fenilalanina na amostra. A reação ocorre em pH próximo de 6,0 e mostra linearidade entre 0,2 e $16 \mathrm{mg} / \mathrm{d}^{27}$.

\section{CONSIDERAÇÕES FINAIS}

Os dados preliminares do Programa Nacional de Triagem Neonatal (PNTN), do Ministério da Saúde, de setembro de 2003, nos 31 SRTN (Serviços Regionais de Triagem Neonatal) credenciados, em 23 estados brasileiros, têm diagnosticados 985 pacientes com fenilcetonúria. Os resultados da pesquisa em 12 estados brasileiros, identificaram 1225 casos. Admite-se que possam existir mais casos de fenilcetonúria no País, muitos ainda desconhecidos e sem tratamento, principalmente em indivíduos com idade superior a 15 anos, os quais estariam com suas funções neurológicas comprometidas.

Diante de assunto de relevada importância, depara-se com a dificuldade maior do tratamento da fenilcetonúria e da conseqüente prevenção da deficiência mental: a falta de alimentos específicos, visto que o tratamento é fundamentalmente dietético e consiste na exclusão de alimentos protéicos e no controle rigoroso da fenilalanina contida nos alimentos. Nessa direção, muito trabalho há por fazer, principalmente na pesquisa e produção de alimentos específicos.

\section{A GRADECIMENTOS}

Agradecemos a colaboração do Conselho Nacional de Desenvolvimento Científico e Tecnológico (CNPq), à Associação do Fenilcetonúricos e Hemocistinúricos do Paraná, aos Centros de Tratamento de Fenilcetonúria no Brasil, ao Ministério da Saúde e à Associação Brasileira de Triagem Neonatal.

\section{RE FER Ê N CIAS}

1. Carvalho TM. Resultados do levantamento epidemiológico da sociedade brasileira de triagem neonatal (SBTN). Rev Méd Minas Gerais. 2003; 13(1 Supl 2):S109-35.

2. Brasil. Lei Federal 8.069 de 13 de julho de 1990. Dispõe sobre o Estatuto da Criança e do Adolescente [Internet]. Brasília; 1990. [acesso 10 mar 2005]. Disponível em: www.presidencia. gov.br/CCivil/Leis/L8069.htm

3. Associação de Fenilcetonúricos e Homocistinúricos do Paraná. Fenilcetonúria. Curitiba: Fundação Ecumênica de Proteção ao Excepcional; 1999. 10p. Publicação Técnica.

4. Moats RA, Koch R, Moseley K, Guldberg P, Gutter $F$, Boles RG. Brain phenylalanine concentration in the management of adults with phenylketonuria. J Inherit Metab Dis. 2000; 23(1):7-14.

5. Shils ME, Olson JÁ, Shike M. Modern nutrition in health and disease. 8th ed. Philadelphia: Lea \& Febiger; 1994. p.1153-68.

6. Mira NVM, Marquez UML. Importância do diagnóstico e tratamento da Fenilcetonúria. Rev Saúde Pública. 2000; 34(1):86-96.

7. Elsas JE, Longo N, Rosenberg LE. Distúrbios hereditários do metabolismo e do armazenamento dos aminoácidos. In: Faucy AS, Braunwald E, Isselbacher KJ, Wilson JD, Martin JB, Kasper DL, editores. Harrison medicina interna. 14. ed. Rio de Janeiro: McGraw-Hill; 1998. p.2329-34.

8. Sheard NF. Importance of diet in maternal phenylketonuria. Nutr Rev. 2000; 58(8):236-9.

9. Sarkissian CN, Gámez, A. Phenylalanine ammonia lyase, enzyme substitution therapy for phenylketonuria, where are we now? Mol Gen Metab. 2005, 86(Suppl 1):22-6.

10. Diament AJ. Erros inatos do metabolismo: aminoacidopatias. In: Diament AJ, Cypel S, coordenadores. Neurologia infantil. 3.ed. São Paulo: Atheneu; 1998. p.372-85.

11. Waitzberg DL. Nutrição oral, enteral e parenteral na prática clínica. 3.ed. São Paulo: Atheneu; 2000. p.449-57.

12. Smith I, Brenton DP. Hiperphenylalaninemias. In: Fernandes J, Saudubray J-M, van Den Berghe G, editores. Inborn metabolic diseases. 2nd ed. New York: Springer-Verlag; 1995. p.147-60.

13. Tourian A, Sidbury JB. Phenylketonuria and hiperphenylalaninemia. In: Stambury JB, Wyngaarden JB, Fredrickson DS, Doldstein, JL, Brown MS. The metabolic basis of inherited disease. 5th ed. New York: McGraw-Hill; 1983. p.270-84.

14. Scriver CR, Kaufman S, Eisensmith RC, Woo SLC. The hiperphenylalaninemias. In: Scriver RS, Beaudet AL, Sly WS, Valle D, editors. The metabolic 
and molecular bases of inherited disease. 7th ed. New York: McGraw-Hill; 1995. p.1015-75.

15. Acosta PB, Yannicelli S. Ross Metabolic Formula System: Nutrition Support Protocols, 4th ed. Columbus (OH): Ross Laboratories; 2001.

16. Fauci AS, Braunwald E, Isselbacher KJ, Wilson JD, Martin JB, Kasper DL, et al. Harrison medicina interna.14.ed. Rio de Janeiro: McGraw-Hill; 1998.

17. Battistini S, Stefano N, Parlanti S, Federico A. Unexpected white matter changes in an early treated PKU case and improvement after dietary treatment. Functional Neurol. 1991; 6(2):177-80.

18. Ishimaru K, Tamasawa, N, Baba, M, Matsunaga M, Takeg K. Phenylketonuria with adult-onset neurological manifestation. Clinical Neurol. 1993; 33(9):961-5.

19. Thompson AJ, Tillotson S, Smith I, Kendall B, Moore SG, Brenton DP. Neurological deterioration in young adults with phenylketonuria. Lancet. 1990; 336(8715):602-5.

20. Villasana D, Butler IG, Williams JC, Roongta SM. Neurological deterioration in adult phenylketonuria. J Inher Metab Dis. 1989; 12(4):451-7.

21. Karam SM. Gestantes com Fenilcetonúria. Rev Méd Minas Gerais. 2003; 13(1 Supl 2):S109-35.

22. Cerone R, Barella C, Fantasia AR, Schialfino MC. Valutazione di una nuova miscela di aminoacidi per il trattamento della fenilchetonuria. Minerva
Pediatr [Internet]. 1999. [cited 2000 Nov 15]. 51(1112):403-6. Available from: http:/www.bireme.br/ ocgi-bin/wxislind.exe/iah/online

23. Brasil. Ministério da Saúde [Internet]. Brasília; 2001. Portaria n. 822/GM de 6 de junho de 2001. Institui no âmbito do Sistema Único de Saúde, o Programa Nacional de Triagem Neonatal/PNTN. [Acesso 10 mar 2005]. Disponível em: http:// dtr2001.saude.gov.br/sas/ PORTARIAS/Port2004/ Gm/GM-2695.htm

24. Ramalho RJR, Ramalho ARO, Oliveira CRP, Oliveira MHA. Evolução do programa de triagem para o Hipotireoidismo Congênito e Fenilcetonúria no Estado de Sergipe de 1995 a 2003. Arq Bras Endocrinol Metab. 2004; 48(6):890-6.

25. Carvalho TM, Vargas PR, Santos HMP. Dados preliminares. Rev Méd Minas Gerais. 2003; 13(1 Supl 2):S40-106.

26. Neonatal phenylalanine test kit. Norton $(\mathrm{OH})$ : Perking elmer life Sciences Inc; 2001. Technical Bulletin.

27. Instituto Brasileiro de Geografia e Estatística [Internet]. Rio de Janeiro; 2000. [acesso 17 maio 2002]. Censo demográfico 2000. Disponível em: http://www.ibge.net/home/estatística/populacao/ censo2000/tabelagrandesregioes211.shtm

Recebido em: 25/6/2004

Versão final reapresentada em: 1/8/2005 Aprovado em: 22/9/2005 